\title{
U2 Small Nuclear Ribonucleoprotein Auxiliary Factor 35 kDa Subunit-Related Protein 2
}

National Cancer Institute

\section{Source}

National Cancer Institute. U2 Small Nuclear Ribonucleoprotein Auxiliary Factor 35 kDa

Subunit-Related Protein 2. NCI Thesaurus. Code C101122.

U2 small nuclear ribonucleoprotein auxiliary factor 35 kDa subunit-related protein 2 (482

aa, $\sim 58 \mathrm{kDa}$ ) is encoded by the human ZRSR2 gene. This protein is involved in the modulation of messenger RNA maturation. 